\title{
Second Heart Sound
}

\author{
Lokanath Seepana ${ }^{1, \odot}$ Dayasagar Rao Vala² \\ ${ }^{1}$ Department of Cardiology, Krishna Institute of Medical Sciences \\ Hospital, Hyderabad, Telangana, India \\ 2Department of Interventional Cardiology, Krishna Institute of \\ Medical Sciences (KIMS) Hospital, Hyderabad, Telangana, India \\ Ind J Car Dis Wom 2020;5:76-86
}

\begin{abstract}
Address for correspondence Dr. Lokanath Seepana, DNB, Department of Cardiology, 1-8-31/1, Minister Road, Krishna Nagar Colony, Begumpet, Secunderabad, Telangana 500003, India (e-mail: lokseepana@yahoo.co.in).
\end{abstract}
Abstract
Keywords
- split second heart sound
- hangout interval
- loud A2
- loud P2
- single second heart sound
- wide fixed splitting
- paradoxical splitting

The auscultation of second heart sound reveals presence of the disease and its pathophysiology, conduction defects, ventricular function, and hemodynamics around the aortic and pulmonary valves. To understand the splitting of the second heart sound, it is useful to understand the concepts of hangout interval and ejection time. Differential diagnosis of S2 split include opening snap, third heart sound, and pericardial knock. Variations of second heart sound may involve intensity or variations of split. Variations of split can be single heart sound, wide split, wide fixed split, or paradoxical splitting. Interpretation of second heart sound in congenital heart disease provides information about the presence and position of semilunar valves.

\section{Introduction}

The auscultation of second heart sound reveals presence of the disease and its pathophysiology, conduction defects, ventricular function, and hemodynamics around the aortic and pulmonary valves. Leatham has rightly emphasized the importance of second heart sound in cardiac auscultation by labeling it "the key to auscultation of the heart." It is formed by two components: aortic and pulmonary. In this review, we discuss the mechanism of generation and splitting of second heart sound and conditions with altered second heart sound.

\section{History}

In 1832, Rounat demonstrated that the second heart sound results from closure of the semilunar valves. ${ }^{2}$ In 1865 , on the basis of clinical observations, Potain indicated that the second heart sound may be split into two components and the degree of this splitting may vary with respiration. ${ }^{3}$ In expiration, the two components come closer, while in inspiration, pulmonary valve closure is delayed (P2), which occurs almost invariably in normal subjects, and enables the recognition of aortic valve closure (A2) and pulmonary valve closure (P2); hence, comparing the duration of right and left ventricular systole. Thorough understanding of splitting of the second heart sound is an important part of auscultation of the heart which helps in the bedside diagnosis of physiological murmur, conduction defects, atrial septal defect, pulmonary stenosis, and ventricular function (Leatham, 1964). Wood (1952) noticed that the second sound in pulmonary hypertension was single with loud pulmonary component. Elaborate work on the second heart sound (S2) was done by many, including Boyer and Chisholm (1958), Shaver (1960), Castle and Jones (1961), and Aygen and Braunwald (1962).

\section{Basics of Human Auscultation}

Sound is defined as a vibration that typically propagates as a pressure wave through a transmission medium such as a gas, liquid, or solid. The human ear receives such waves and their perception by the brain causes sound. Sound waves have three measurable parameters: intensity, frequency, and timbre or quality.

\section{Intensity or Loudness}

The height of a pressure wave is called as the amplitude (-Fig. 1). This height determines the perception of loudness.
(C)2020 Women in Cardiology and Related Sciences
License terms

() (1) $\ominus \circledast$ 

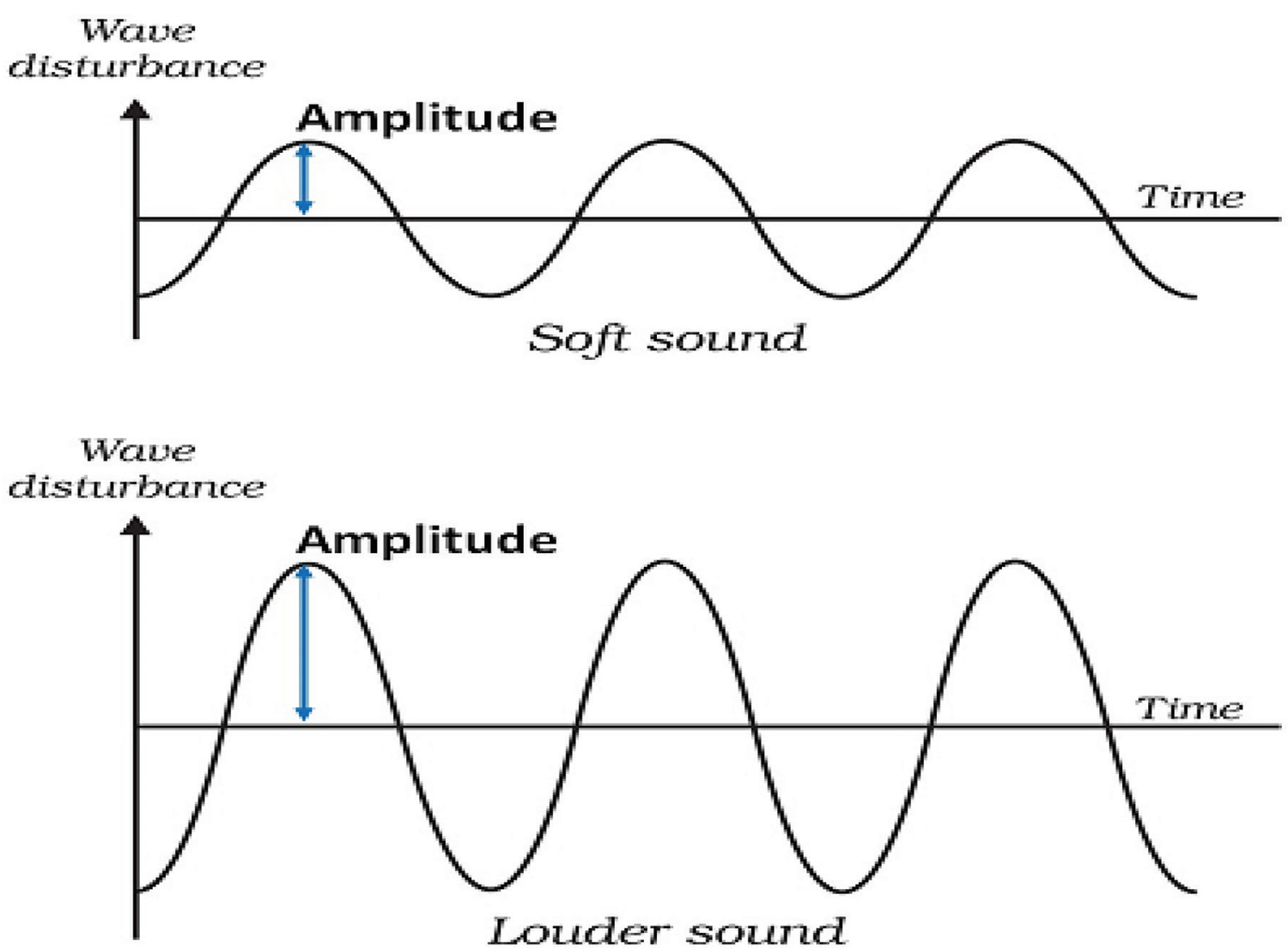

Fig. 1 Amplitude of soft and loud sounds.

To accommodate the wide range, sound amplitudes are measured on a logarithmic scale. The unit of measurement is the decibel $(\mathrm{dB})$. The quietest sound intensity that humans can hear is $0 \mathrm{~dB}$. Zero decibel does not mean that there is no sound, as we cannot hear it. Zero decibel is labeled as the hearing threshold of human ear. Sound measured at $10 \mathrm{~dB}$ implies 10 times the intensity of this reference value, $20 \mathrm{~dB}$ is 100 times and so on.

\section{Frequency or Pitch}

The distance between the highest point of one pressure wave to the next is known as the wavelength (-Fig. 2). The number of these waves crossed per second is the frequency which is measured in Hertz $(\mathrm{Hz})$. The frequency of sound wave determines the perception of pitch. The audible frequency range extends from 20 to $20,000 \mathrm{~Hz}$. The human ear can hear sounds between 500 and $4000 \mathrm{~Hz}$. The majority of heart sounds and murmurs range between 5 and $800 \mathrm{~Hz}$.

\section{Quality or Timbre}

Other than amplitude and frequency, factor which affect the perception of a sound or murmur includes quality

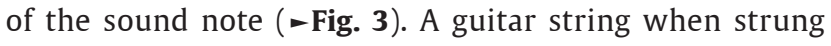
vibrates along its whole length and also in segments. The vibration of the whole string produces the fundamental or primary frequency and the segmental vibrations form secondary frequencies which make up the harmonics. The timbre or quality of a sound comprise these primary and secondary frequencies of the complex waveform. These secondary frequencies differentiate a violin or piano playing the same note. A variety of terms were used to qualify heart murmurs like harsh midsystolic murmur or soft-blowing pansystolic murmur.

\section{Technique}

The examination should be performed in a cozy and quiet room. Begin the cardiac auscultation for the second heart sound with the stethoscope placed at the second right intercostal space. The second sound is analyzed by auscultating over the second left intercostal space, followed by the fourth left intercostal space along the left sternal border at first and then cardiac apex. When listening to the heart sounds, it is advisable to simultaneously palpate either the carotid artery or apex impulse to identify the onset of systole. Standard observation regarding the heart sound auscultation in normal subjects is that A2 is the loudest sound on auscultation in all areas including mitral area because of the higher systemic arterial resistance compared with the pulmonary arterial resistance which is normally 10 times higher. P2 is the softest and localized to pulmonary area and not audible over the apex. 

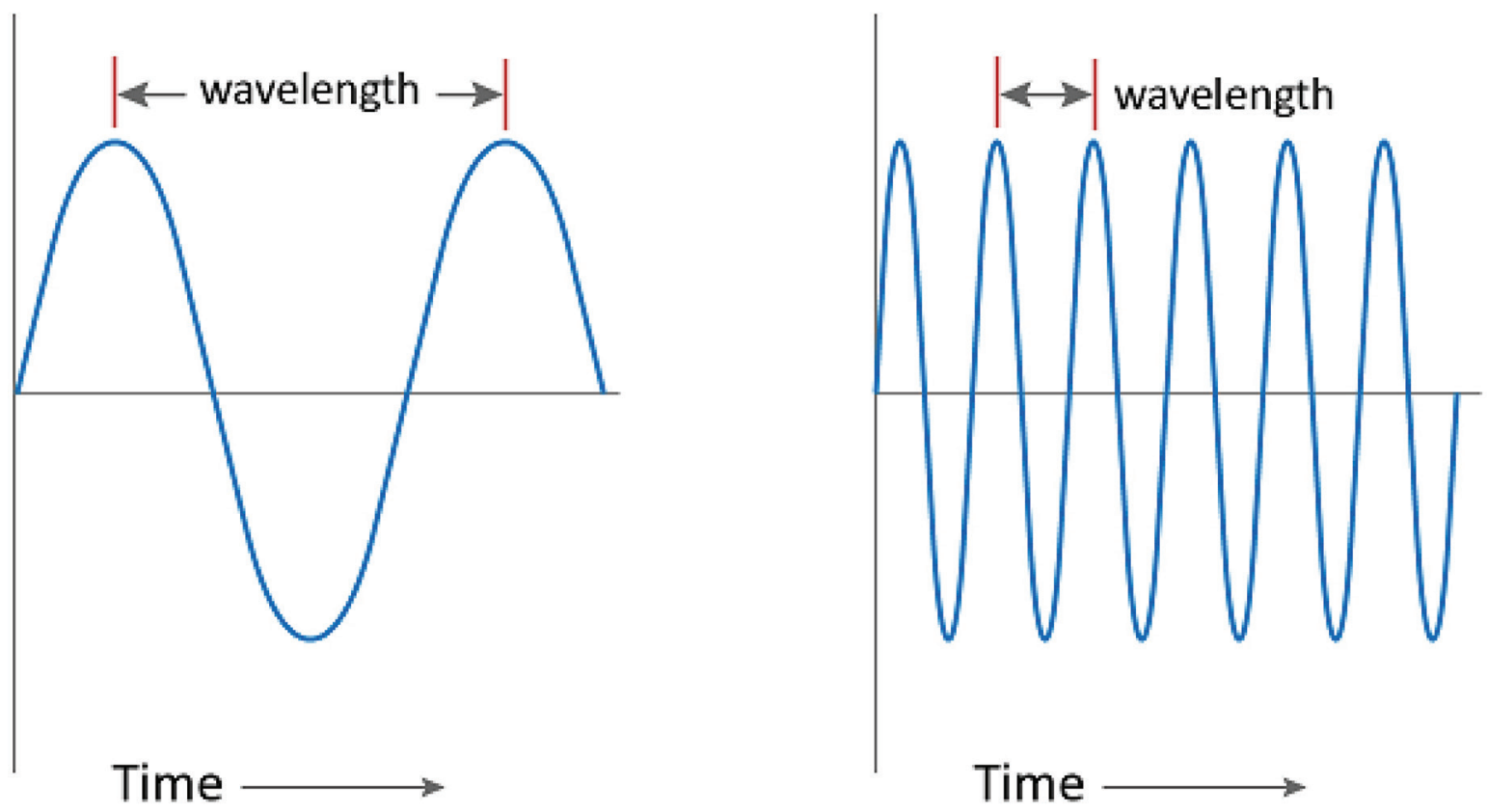

Fig. 2 Low pitch versus high pitched sound.

\section{Tuning fork}

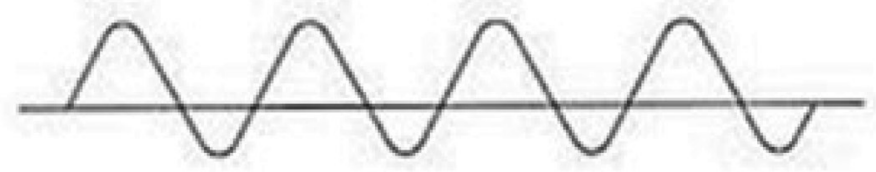

Flute

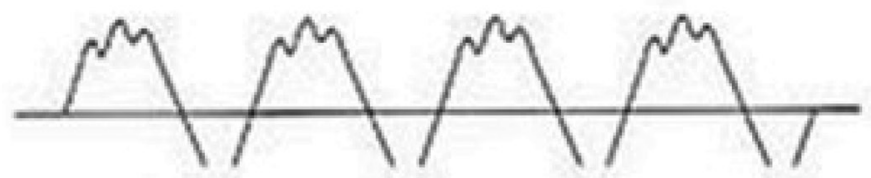

Voice
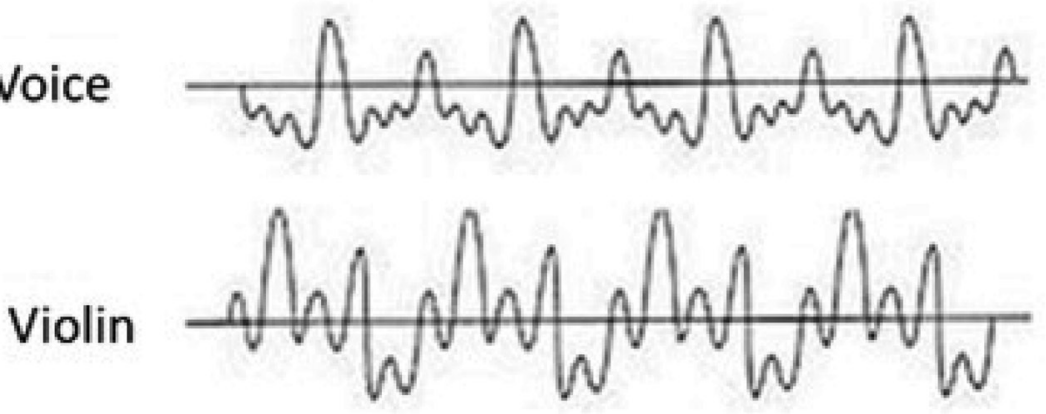

Fig. 3 Timbre of various instruments. ${ }^{4}$

To appreciate splitting of S2, slowly move the stethoscope ("inching") from the second right intercostal space to the fourth left intercostal space. The examiner should note respiratory variation both during quiet breathing and during deep breathing. Slow and routine respiration is best for auscultation because deep breath may damp pulmonic sound by interposing lung tissue over the stethoscope. The interval between the two components of the second heart sound normally widen on inspiration and virtually disappears on expiration. Audible splitting of second heart sound during inspiration generally occurs three or more cardiac cycles after the onset of inspiration. This represents the time taken for the differentiated preload to be manifest (increased venous return to right side and decreased venous return to the left side) consequent to lung expansion, accommodating the increased right ventricular output. In contrast, in patients with constrictive pericarditis, there is immediate splitting of second heart sound at the onset of inspiration, which is 
a consequence of exaggerated ventricular interaction. The best position for examining the split second heart sound is standing or sitting position, as wide split S2 is present as a normal variant in some young subjects. Hence, wide split in both supine position and standing position is abnormal. The Valsalva maneuver further exaggerates splitting of the second sound.

\section{How to Recognize $A 2$ and $P 2$}

The best way to recognize the $\mathrm{A} 2$ and $\mathrm{P} 2$ is making use of the inching technique. First, start auscultating the pulmonary area. Identify the loudest component of the two, which is A2. Slowly move toward the apex by moving along the left parasternum, identifying the loudest component aortic sound A2. The sound that is constantly loud and heard with nearly the same intensity while inching from pulmonary area toward apex is identified as aortic sound $\mathrm{A} 2$, and the one whose intensity slowly muffles and is absent at the mitral area is identified as pulmonic sound P2. The secret of auscultation of second heart sound lies in auscultation of split S2 in expiration, which could hint about either a wide fixed/variable split or paradoxical split.

\section{Normal Physiology}

The second heart sound is usually sharper, shorter, and louder in intensity compared with first heart sound, as the semilunar valve closure occur at much higher pressures than the $\mathrm{A}-\mathrm{V}$ valves, and the energy pumped into blood is much greater. Second heart sound marks the offset of systole and onset of diastole. Second heart sound is caused by the closure of the semilunar valves which result in sudden deceleration of the blood column due to closed valves producing vibrations in the cardiohemic system. Simultaneous recording of electrocardiogram, phonocarotid pulse tracing, and echocardiogram revealed occurrence of A2 and P2 on phonocardiogram 10 to $30 \mathrm{msec}$ after the actual closure of the semilunar valves, indicating that actual closure does not cause sound but deceleration of column of blood consequent to closure which, in turn, causes vibration of cardiohemic system, resulting in sounds.

To understand the splitting of the second heart sound, it is useful to understand the concepts of hangout interval and ejection time (-Fig. 4).

The heart pumps blood into the arterial system, causing distension of the elastic arteries, and thereby producing the arterial pressure pulse wave. With continued ejection, ventricular pressure falls and the arterial pressure rises. The semilunar valves are expected to close at this point of crossover of pressures between ventricles and arteries; however, they do not close at this point in reality. The semilunar valves close a bit late after the crossover of pressures at incisura. With continued ejection of blood into arteries, the volume in the elastic arteries fall further and intraventricular pressure falls suddenly, causing the aortic valve to close at an aortic pressure called the incisura of the aortic pulse wave, which is identical to the dicrotic notch of arterial pulse wave. The semilunar valves close at the incisura in reality. The duration between the crossover of pressures between left ventricle-aorta and right ventricle-pulmonary artery and the

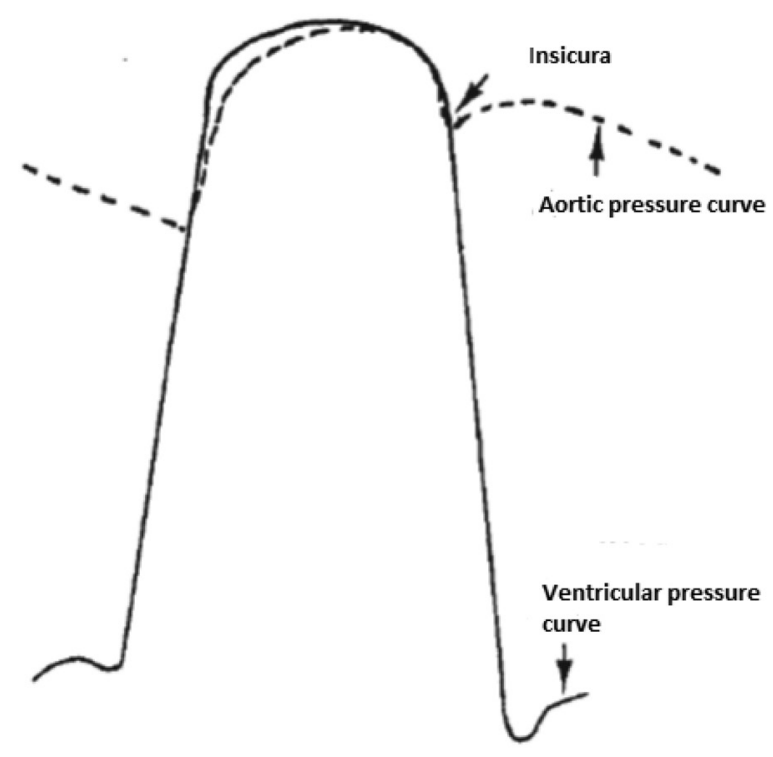

Fig. 4 This is the superimposed image of the left ventricular pressure tracing and aortic pressure tracing. As the left ventricular pressure increases and crosses the aortic pressure, aortic valve opens and blood gets ejected. As the blood is ejecting, the left ventricular pressure slowly falls and when below the aortic diastolic pressure at end of ejection, aortic valve closes. The point at which the ejection is finished and left ventricular and aortic pressure curves separate is called incisura and coincides with the aortic second heart sound. ${ }^{5}$

incisura is defined as the hangout interval. To simplify, it is the time interval between the expected closure and actual closure of the semilunar valves. Second heart sound is expected at the crossover of pressures but actual closure occurs at the incisura. When the pressure curves of the pulmonary artery and right ventricle are recorded simultaneously, the pulmonary artery curve at the level of the incisura (dicrotic notch) falls behind the right ventricular curve or "hangs out" after it. It should be noted that the hangout interval is a self-explanatory term coined by Shaver and associates for their convenience to measure the capacitance of the arterial system. This interval will not define any specific physiologic event, but gives a fair idea about the resistance and capacitance of the vascular bed into which blood is being ejected. The most significant accomplishment of the "hangout" interval is it simplified the concepts of the complex interplay of the left and right ventricular ejection with the impedance of the systemic and pulmonary circulations. The hangout interval on the aortic side is approximately $30 \mathrm{msec}$ compared with $80 \mathrm{msec}$ on pulmonary artery side. In younger people, maximal splitting during inspiration is 40 to $50 \mathrm{msec}$ due to longer hangout interval which decreases with age. In people 40 years and older, a single S2 during inspiration and expiration may be normal.

\section{Factors Affecting the Hangout Interval}

Factors affecting the hangout interval are as follows:

1. Impedance or resistance to the forward flow (probably the most important factor).

2. Distensibility or compliance of the vessel wall.

3. Phase of respiration. 
Hangout interval is inversely proportional to the vascular impedance (as the vascular impedance of aorta is high, hangout interval is short on aortic side and longer hangout interval on pulmonary side is due to low impedance, as the pulmonary vascular bed is large). Hangout interval is directly proportional to the vascular compliance. As the pulmonary vascular compliance is high compared with aortic compliance, it has a higher hangout interval. Inspiration by stretching the pulmonary vasculature increases the hangout interval. Thus, the hangout interval is an acceptable, easily measurable interval determined from the cardiac cycle and is a good reflection of the total impedance of the arterial system. Ejection time represents the interval from beginning to termination of the blood flow from the ventricles. The higher the hangout interval, the higher the ejection time (-Fig. $\mathbf{5}$ ).

\section{Mechanism of Splitting of Second Heart Sound}

Nonparallel closure of these aortic and pulmonary valves is responsible for the splitting of second heart sound. For the split to be normally audible to the human ear, the split should be at least $30 \mathrm{msec}$. During inspiration, the split is 40 to $60 \mathrm{msec}$, while in expiration, it is approximately 10 msec. Normal physiological splitting is splitting of second heart sound during inspiration and single sound during expiration. There are three mechanisms proposed for the normal physiological splitting of second heart sound.

\section{Delayed closure of the pulmonary valve:}

During the inspiration, there is an increase in the filling of the right ventricle from its large venous pool in the right auricle and great veins. Consequently, there is a prolongation of right ventricular systole, which is reflected by increased right ventricular ejection time, with the result that the pulmonary valve closes after the aortic. This is the mechanism of the delayed closure of the pulmonary valve.

2. There is also a fall in the pressure of the pulmonary artery during inspiration, due to which hangout interval on right side increases, which could contribute to delayed closure of the pulmonary valve.

3. Earlier closure of aortic valve.

Mechanism for earlier closure of aortic valve during inspiration compared with expiration was put forth by Shaver based on findings by Harris and Sutton, showing that the aortic valve closed earlier during inspiration compared with expiration. ${ }^{7}$ The purported mechanism for this is that the blood from the increased right ventricular output during inspiration reaches the left ventricle after passing through the vascular bed, and therefore does not reach the left ventricle for a few heartbeats, by which point the patient will be

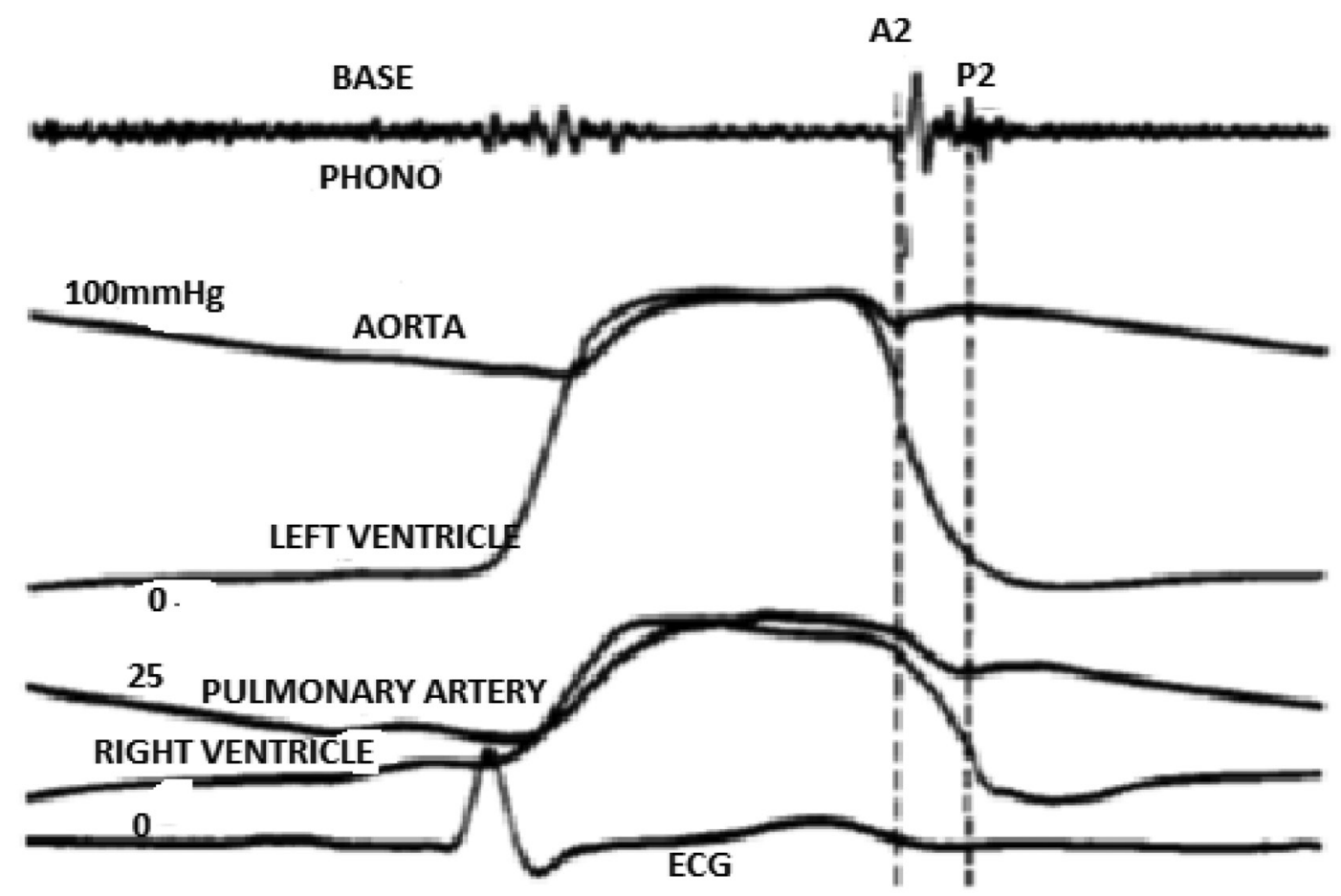

Fig. 5 The cardiac cycle is recorded by high-fidelity catheter-tipped micromanometers. The aortic (A2) and pulmonic (P2) closure sounds occur simultaneously with the incisurae of their respective arterial traces. The figure also shows that the time of systole of both right and left ventricles is similar and the right ventricular ejection period is more delayed than left ventricular ejection due to a high, right-sided hangout interval. Abbreviation: ECG: electrocardiogram. ${ }^{6}$ 
in expiration. As a result, this increased volume prolongs the left ventricular ejection time during the following expiratory phase. Therefore, the closure of the aortic valve is comparatively earlier during inspiration than expiration. ${ }^{8}$

During inspiration, blood is held back in pulmonary circulation and there is a consequently decreased preload of left ventricle. As a result, ejection time is shortened and there is earlier closure of A2. The relative contribution for the increased time interval of wide S2 split by delayed P2 and early A2 is $66 \%$ and $33 \%$, respectively.

During sustained arrhythmias, particularly atrial fibrillation or frequent PVCs, proper evaluation of respiratory splitting can be difficult. In atrial fibrillation, S2 splitting usually is wider after the long cycle lengths, as the longer cycle lengths allow more time for filling in diastole. PVCs may induce alterations in S2 synchrony and disruption in the basic rhythm by causing additional heart sounds during the ectopic beats.

\section{Effect of Valsalva Maneuver on the Second Heart Sound Split}

Release of Valsalva strain amplifies the auscultatory effect of inspiration on the second heart sound. There are four phases of Valsalva maneuver: phase of onset of strain, followed by phase of continued strain, phase of release, and phase of recovery. There is increase in intrathoracic pressure during the onset and continued strain phase which drops suddenly during the release phase of strain due to which there is a sudden gush of systemic venous blood into the right heart chambers, making the normal inspiratory splitting of the second heart sound more apparent on Valsalva release. An important exception to the above rule is a large atrial septal defect (ASD) where the sudden increased preload will move freely into both ventricles, causing wide fixed split unaffected by Valsalva maneuver. Conditions where Valsalva release will continue to have wide varying split in patients with atrial septal defect are as follows:

1. Atrial septal defect with right bundle branch block.

2. In patients with partial anomalous pulmonary venous return and an intact atrial septum.

Differential diagnosis of S2 split includes opening snap, third heart sound, and pericardial knock (- Table 1).

\section{Variations of Second Heart Sound}

Variations of the second heart sound could be either one of the following characteristics:

1. Amplitude or intensity-loud/soft/muffled/absent.

2. Variations of split.

The loudness or intensity of the S2 is determined by the grading system in relation to $\mathrm{S} 1$. The sounds with loudness grades IV to VI are abnormally loud. When S2 is either inaudible or grade I in loudness, it could be considered decreased when $\mathrm{S} 1$ or other sounds are normal.

The loudness of the sound can be graded using the Levine system of grading murmurs, which has six categories of loudness: the grades I to III are not loud enough to be palpable, whereas grades IV to VI are loud and palpable. The grade I sound is very faint. The grade II sound is just audible. The grade III sound is the loudest audible sound without being palpable. The grade IV sound is both loud and palpable, requiring full contact of the stethoscope against the chest wall. The grade V sound is heard with stethoscope

Table 1 Differential diagnosis of s2 split include opening snap, third heart sound, and pericardial knock

\begin{tabular}{|c|c|c|c|c|}
\hline & Split S2 & Opening snap & Third heart sound & Pericardial knock \\
\hline Cause & $\begin{array}{l}\text { Closure of semilunar } \\
\text { valves }\end{array}$ & $\begin{array}{l}\text { Opening of atrioventricular } \\
\text { valves }\end{array}$ & $\begin{array}{l}\text { Passive filling of the } \\
\text { ventricles }\end{array}$ & $\begin{array}{l}\text { Sudden cessation } \\
\text { of rapid ventricular } \\
\text { filling due to } \\
\text { pericardial } \\
\text { constraint }\end{array}$ \\
\hline Pitch & High & High & Low & High \\
\hline Duration & A2-P2 gap-30-50 msec & A2-OS gap-30-120 msec & A2-S3 gap-120-160 msec & $\begin{array}{l}\text { A2 pericardial knock } \\
\text { gap- } 120-140 \text { msec }\end{array}$ \\
\hline Location & $\begin{array}{l}2 \& 3 \text { interspaces } \\
\text { left parasternum } \\
\text { with diaphragm of } \\
\text { stethoscope }\end{array}$ & $\begin{array}{l}4 \text { \& } 5 \text { interspaces left } \\
\text { parasternum in standing } \\
\text { position with diaphragm of } \\
\text { stethoscope }\end{array}$ & $\begin{array}{l}\text { Left-sided S3-at } \\
\text { apex in left lateral } \\
\text { position: right-sided } \\
\text { S3-5 } 5^{\text {th }} \text { interspace left } \\
\text { parasternum with bell of } \\
\text { stethoscope }\end{array}$ & $\begin{array}{l}4 \text { and } 5 \text { interspaces } \\
\text { left parasternum }\end{array}$ \\
\hline $\begin{array}{l}\text { Variation with } \\
\text { respiration }\end{array}$ & Varies & No variation & No variation & No variation \\
\hline $\begin{array}{l}\text { Associated } \\
\text { features }\end{array}$ & & Mid diastolic murmur & Raised JVP & $\begin{array}{l}\text { Raised JVP with } \\
\text { prominent } Y \text { descent }\end{array}$ \\
\hline
\end{tabular}

Abbreviation: JVP, jugular venous pressure. 
partly off the chest. The grade VI sound can be heard with the stethoscope completely off the chest wall. ${ }^{9}$

\section{Intensity of S2}

The factors affecting the intensity of the S2 are as follows:

1. Pressure distal to the semilunar valve (systemic hypertension and pulmonary hypertension).

2. Dilatation of the root of great vessels (aortic aneurysm, idiopathic dilatation of the pulmonary artery).

3. Increased flow of blood across the aortic valve (high-output states like anemia, thyrotoxicosis, beriberi, and Paget's disease).

4. Condition of the semilunar valves-mobile or fixed.

Systemic hypertension and pulmonary hypertension will bang the semilunar valves with more force so that it causes a loud S2 (-Tables 2 and 3). More energy is dissipated to the structures surrounding the semilunar valve as the valves suddenly close, causing the column of blood to suddenly cease transferring the energy. Increased flow across the semilunar valves cause loud S2. Dilatation of vessel beyond semilunar valves cause the aorta and proximal pulmonary artery to come near corresponding areas, causing loud A2P2. Increased flow across the semilunar valves cause loud S2 in hyperkinetic circulation. Accentuated P2 is sine quo non for pulmonary hypertension. Only condition with loud P2 without pulmonary hypertension is ostium secundum ASD which is probably related both to the increased size of the right ventricle which forms the cardiac apex, dilatation of the pulmonary artery, and increased flow across the valve. The diagnostic reliance of P2 for diagnosing pulmonary hypertension in atrial septal defect is low. However, if the intensity of P2 is very loud or if intensity increases after exercise, it suggests ASD with pulmonary hypertension.

Criteria for loud P2:

1. Intensity of P2 equal to or more than A2.

2. Audible P2 at apex.

\section{Grading of Accentuated or Loud P2}

1. Mild or grade $1(+)$ : when intensity of P2 is equal to A2: occurs in mild pulmonary hypertension (PH) (systolic pressure: 30-49 mm Hg, mean pressure: 21-34 mm Hg).

2. Moderate or grade $2(++)$ : when intensity of P2 exceeds A2, that is, P2 is louder than A2: occurs in moderate $\mathrm{PH}$ (systolic pressure: $50-75 \mathrm{~mm} \mathrm{Hg}$, mean pressure: 35-50 mm Hg).

3. Severe or grade $3(+++)$ : when P2 is loud and banging and is audible beyond the pulmonary area: occurs in severe $\mathrm{PH}$ (systolic pressure: > $75 \mathrm{~mm} \mathrm{Hg}$, mean pressure > $50 \mathrm{~mm} \mathrm{Hg}$ )

\section{Decreased Intensity of Second Heart Sound}

In valvular and supravalvular aortic stenosis, the A2 is muffled due to decreased excursion of the fibrosed aortic valve

Table 2 Causes and mechanisms of loud A2

\begin{tabular}{|l|l|}
\hline Systemic hypertension & Increased pressure distal to aortic valve \\
\hline Aneurysm of ascending aorta & Dilatation of aortic root \\
\hline Congenital Bicuspid aortic valve & Increased thickness of mobile aortic leaflets \\
\hline Aortic regurgitation due to aortic root dilatation & Dilatation of aortic root with normal leaflets and increased flow across the valve \\
\hline Thin chest wall, straight back syndrome & Aorta becomes more near to the chest wall \\
\hline Hyperkinetic circulatory states & Increased flow across the aortic valve \\
\hline
\end{tabular}

Table 3 Causes and mechanisms of loud pulmonary heart sound

\begin{tabular}{|l|l|}
\hline Pulmonary hypertension & High-pressure distal to pulmonary valve \\
\hline Ostium secundum atrial septal defect & Increased size of right ventricle and increased flow across the pulmonary valve \\
\hline Left to right shunts & Increased flow across the pulmonary valve \\
\hline Thin chest wall, straight back syndrome & Pulmonary artery becomes more near to the chest wall \\
\hline Hyperkinetic circulatory states & Increased flow across the aortic valve \\
\hline
\end{tabular}

Table 4 Causes and mechanisms of muffled A2

\begin{tabular}{|l|l|}
\hline Valvular and supravalvular aortic stenosis & Decreased mobility of valve leaflets, decreased flow across aortic valve \\
\hline Congestive cardiac failure & $\begin{array}{l}\text { Decreased flow across valve because of low stroke volume and increased peripheral } \\
\text { resistance }\end{array}$ \\
\hline Aortic regurgitation with left heart failure & Due to decreased stroke volume \\
\hline
\end{tabular}

Table 5 Causes and mechanism of muffled P2

\begin{tabular}{|l|l|}
\hline Pulmonic stenosis & Decreased valve excursion \\
\hline Thick chest wall & Increased distance between valve and chest wall \\
\hline
\end{tabular}


leaflets ( $\mathbf{- T a b l e s} \mathbf{4}$ and $\mathbf{5}$ ). Intensity of A2 is not affected in subvalvular aortic stenosis and hypertrophic obstructive cardiomyopathy. In congestive cardiac failure, dull second heart sound is on account of decreased flow across valve because of low-stroke volume and high-peripheral vascular resistance. Second heart sound in aortic regurgitation gives us a clue to etiology of aortic regurgitation. Loud and tambour quality of A2 represents dilated aortic root causing incompetence of aortic valve. Soft/muffled A2 in aortic regurgitation represents structural abnormality of leaflets-thickened deformed leaflets or perforation of leaflet.

\section{Variations of S2 Split}

Audible split in inspiration without split in expiration is termed as normal physiological splitting of second heart sound. Pathological splitting could one of the following (-Table 6):

1. No split or single second heart sound.

2. Wide splitting.

3. Wide fixed splitting.

4. Reversed or paradoxical splitting.

\section{Single Second Heart Sound}

Single second heart sound is defined as absence of split in both phases of respiration, neither inspiration nor expiration. In severe pulmonary hypertension, the pulmonic sound is extremely loud and masks the aortic sound by a phenomenon of retrograde masking, making it a single second heart sound ( - Table 7 ). Before labeling second heart sound as single, S2 should be auscultated in both phases of respiration, in supine position with and without passive leg raising and
Valsalva maneuver. In severe pulmonary stenosis with overriding of the aorta (Fallot's tetralogy), most of the blood from the right ventricle preferentially goes into the aorta, with the result that the pulmonary flow is less and the diastolic pressure in the pulmonary artery becomes too low to close the valve firmly and hence inaudible.

\section{Wide Splitting}

Wide splitting is defined as splitting of second heart sound in both phases of respiration. Wide splitting of second heart sound intuitively leads to understanding about wider interval between A2 and P2. Splitting is related to its response to various phases of respiration. It is not related to the time interval between $\mathrm{A} 2$ and P2. At bedside, wide split refers to the behavior of second heart sound in response to respiration, and wide splitting is said to be present if there is split in both phases of respiration.

Abnormally wide splitting is most readily diagnosed during the expiratory phase of continued respiration, when splitting is usually minimal. Wide splitting should be labeled after examining in supine and standing position. The wide splitting can be due to electrical or mechanical delay in closure of the pulmonary valve or early closure of the aortic valve. In right bundle-branch block, the electrical delay in excitation of the right ventricle causes delay in closure of the pulmonary valve. In ASD, there is mechanical delay from increased right-sided flow with no further separation during inspiration. Thus, in ASD, splitting of the second heart sound tends to be wide and fixed and has been found to be a valuable sign in clinical diagnosis. Pulmonary stenosis causes prolongation of right ventricular systole and mechanical delay in closure of the pulmonary valve because of high-pulmonary ejection time.

Table 6 Types of split second heart sound

\begin{tabular}{|l|l|}
\hline Normal physiological splitting & Split audible in inspiration without being audible in expiration \\
\hline Wide splitting & Split audible in both phases of respiration \\
\hline Wide variable splitting & $\begin{array}{l}\text { Split audible in both phases of respiration with slightly longer split in inspiration than } \\
\text { expiration }\end{array}$ \\
\hline Wide fixed splitting & $\begin{array}{l}\text { Splitting audible in both phases of respiration and equal duration in both phases of } \\
\text { respiration }\end{array}$ \\
\hline Reversed or paradoxical splitting & Splitting audible in expiration without being audible in inspiration \\
\hline Single second heart sound or no splitting & Absent split in both phases of respiration \\
\hline
\end{tabular}

Table 7 Causes and mechanisms of single second heart sound

\begin{tabular}{|l|l|}
\hline Aortic stenosis, pulmonary stenosis & Low-flow of blood across the valves \\
\hline Aortic atresia, pulmonary atresia & Atretic semilunar valves \\
\hline Severe pulmonary hypertension & Retrograde masking of A2 due to loud P2 \\
\hline Transposition of great vessels & Posterior location of pulmonic valve \\
\hline Truncus arteriosus, Tetralogy of Fallot & Only one semilunar valve present \\
\hline VSD with Eisenmenger syndrome & $\begin{array}{l}\text { Both ventricles contract as one with the same strength. Same compliance in both } \\
\text { systems }\end{array}$ \\
\hline
\end{tabular}

Abbreviation: VSD, ventricular septal defect. 
Wide splitting of the second heart sound is also caused by early closure of the aortic valve, as in mitral incompetence, where the diminished resistance to left ventricular outflow causes shortening of left ventricular systole ( $\mathbf{- T a b l e s} \mathbf{8}$ and $\mathbf{9}$ ).

\section{Wide Fixed Splitting of Second Heart Sound}

When right or left ventricular stroke volume does not change during inspiration, or when there is a similar degree of respiratory alteration in both right ventricle and left ventricle filling, the splitting of $\mathrm{S} 2$ is fixed. Fixed splitting is more noticeable when the A2-P2 interval is wide. (-Table 10).

The phenomenon of fixed splitting of the second heart sound in ASD has been well-documented. Even with deep inspiration and expiration, the interval between aortic and pulmonic components of the second heart sound in ASD remains constant or moves very slightly (less than $20 \mathrm{msec}$ ), with the sounds never becoming single. A basic hemodynamic expression of ASD is constant right-sided diastolic hypervolemia. The right ventricle apparently takes longer to eject this increased volume; hence, its stroke time (ejection time) is prolonged and the pulmonary valve closes later than the aortic valve. Because the overfilled state is present throughout the respiratory cycle, the right ventricular volume during expiration may not diminish. Conversely, as a result of its already excessive diastolic inflow, the right ventricle apparently does not accept the additional inspiratory augmentation of filling and its stroke volume thus does not increase during inspiration. The result is that aortic and pulmonic valve closures remain constantly separated, with their interval being affected little, if at all, by respiration. The right and left atria act as a common venous reservoir; anything that influences right ventricle or left ventricle filling will alter the degree of left-to-right shunting across the atrial defect. The communication between the two atria and the flow through the defect compensates for varying venous return on both phases of respiration. During inspiration, increase in right ventricular volume causes a decrease in the amount of blood shunted into the right atrium from the left side and expiration; as the venous return decreases,

Table 8 Causes and mechanism of wide split S2 due to changes of A2

\begin{tabular}{|l|l|}
\hline Electrical & \\
\hline Left ventricular pacing, left ventricular ectopic & Early activation of aortic valve compared with pulmonic valve \\
\hline Mechanical delay & Prolonged ejection time of left ventricle due to fixed obstruction \\
\hline Aortic stenosis & $\begin{array}{l}\text { Prolonged ejection time of left ventricle due to dynamic left ventricular outlet } \\
\text { obstruction }\end{array}$ \\
\hline Hypertrophic obstructive cardiomyopathy & Prolonged ejection time due to increased afterload \\
\hline Both mechanical \& electrical & $\begin{array}{l}\text { Delayed electrical activation of left ventricle along with delayed onset of mechanical } \\
\text { contraction }\end{array}$ \\
\hline Myocardial ischemia/infarction & \multicolumn{2}{|l|}{ Decreased systemic impedance, leading to delayed A2 } \\
\hline Miscellaneous & \\
\hline Patent ductus arteriosus &
\end{tabular}

Table 9 Causes and mechanism of wide split S2 due to changes of P2

\begin{tabular}{|l|l|}
\hline Electrical & \\
\hline Right bundle branch block & Delayed activation of right ventricle \\
\hline Mechanical & \\
\hline Moderate to severe pulmonary stenosis & Prolonged ejection time of right ventricle \\
\hline Severe pulmonary hypertension & Delayed emptying of right ventricle due to increased resistance \\
\hline Acute pulmonary embolism & Delayed emptying of right ventricle due to increased resistance \\
\hline Right heart failure & Delayed emptying of right ventricle due to decreased contractility \\
\hline Atrial septal defect & Delayed emptying of right ventricle due increased blood flow on right side \\
\hline
\end{tabular}

Table 10 Causes and mechanism of wide fixed split second heart sound

\begin{tabular}{|l|l|}
\hline Atrial septal defect & $\begin{array}{l}\text { Right and left atria function in syncytium with altering preload and shunt with } \\
\text { respiration }\end{array}$ \\
\hline $\begin{array}{l}\text { All other causes of wide split with right ven- } \\
\text { tricular failure }\end{array}$ & $\begin{array}{l}\text { As right ventricular failure is unable to increase the stroke volume from increased } \\
\text { preload }\end{array}$ \\
\hline
\end{tabular}


there is associated increase in the shunted blood flow from left atrium to right. Thus, the right ventricular volume is almost the same on both phases of respiration, producing a fixed right ventricular ejection time in both inspiration and expiration and explaining the relatively fixed S2 split.

\section{Reversed or Paradoxical Split Second Heart Sound}

Reversed or paradoxical splitting is defined as audible second heart sound splitting in expiration and single sound in inspiration (-Table 11). Normally aortic sound precedes pulmonic sound in both phases of respiration. If pulmonic sound precedes aortic sound, it is labeled as reversed split (-Fig. 6).

\section{Second Heart Sound in Congenital Heart Disease}

If two components of second heart sound are heard, it implies presence of two semilunar valves and rules out truncus arteriosus (single semilunar valve). Audibility of both components is influenced by respective position of semilunar valve with respect to the chest wall. Normally, the pulmonary valve is anterior and its corresponding sound P2 is audible in pulmonary area, even though its intensity is not high. On the contrary, if pulmonary valve is malposed (posterior to aortic valve), it may not be audible even in absence of pulmonic valve stenosis. Thus, single second heart sound in congenital heart disease implies that it may occur due to one of the following reasons:

1. Atresia or severe stenosis of one of the semilunar valves (aortic or pulmonary atresia).

Table 11 Mechanisms and causes of reversed or paradoxical S2 split

\begin{tabular}{|l|l|}
\hline Delayed electrical activation of left ventricle & Right ventricle pacing, right ventricle ectopic, left bundle branch block \\
\hline Delayed mechanical activation of left ventricle & Severe aortic stenosis, systemic hypertension, acute myocardial infarction \\
\hline Early activation of right ventricle & Type B Wolf Parkinson White syndrome \\
\hline Early emptying of right ventricle & Severe tricuspid regurgitation \\
\hline
\end{tabular}

EXPIRATION

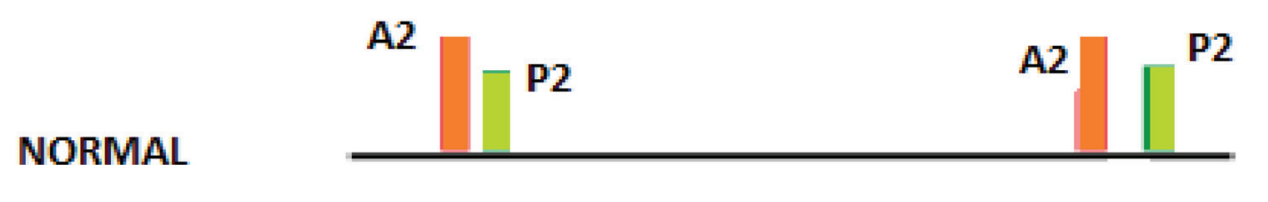

WIDE SPLITTING

\section{INSPIRATION}

NORMAL

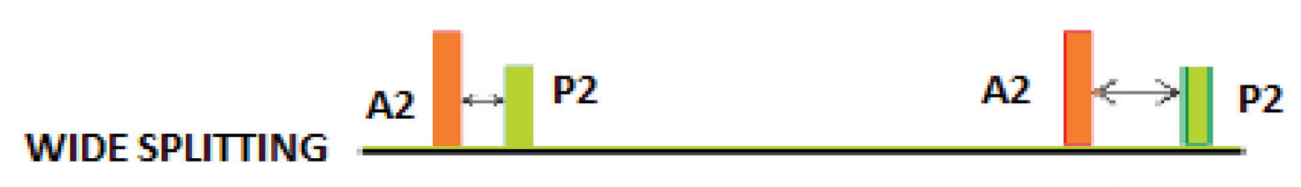

\section{PARADOXICAL SPLITTING}

Fig. 6 Representation of various types of splitting of second heart sound. ${ }^{10}$ 
Table 12 Second heart sound in Eisenmenger Syndrome

\begin{tabular}{|l|l|l|l|}
\hline & $\begin{array}{l}\text { With left to right shunt } \\
\text { and without pulmonary } \\
\text { hypertension }\end{array}$ & $\begin{array}{l}\text { With left to right shunt and } \\
\text { pulmonary hypertension }\end{array}$ & $\begin{array}{l}\text { Bidirectional shunting } \\
\text { (Eisenmenger syndrome) }\end{array}$ \\
\hline Atrial septal defect & $\begin{array}{l}\text { Wide fixed split with A2 equal } \\
\text { in intensity in P2 in pulmo- } \\
\text { nary area. Additional ejection } \\
\text { systolic murmur and tricuspid } \\
\text { flow diastolic murmur noted }\end{array}$ & $\begin{array}{l}\text { Wide fixed split with A2 equal } \\
\text { in intensity in P2 in mitral } \\
\text { area. }\end{array}$ & $\begin{array}{l}\text { Wide fixed split with P2 equal } \\
\text { in intensity in A2 in pulmo- } \\
\text { nary area. No ejection systolic } \\
\text { murmur and tricuspid flow } \\
\text { diastolic murmur }\end{array}$ \\
\hline Ventricular septal defect & $\begin{array}{l}\text { Physiological split or wide split, } \\
\text { A2 louder than P2 in pulmonary } \\
\text { area and P2 never transmitted } \\
\text { to mitral area }\end{array}$ & $\begin{array}{l}\text { Physiological split or wide } \\
\text { split, P2 louder than A2 in pul- } \\
\text { monary area and P2 occasion- } \\
\text { ally transmitted to mitral area }\end{array}$ & $\begin{array}{l}\text { S2 is single and pulmonary sound and murmur } \\
\text { heard }\end{array}$ \\
\hline Patent ductus arteriosus & $\begin{array}{l}\text { S2 split could be physiological } \\
\text { or reversed }\end{array}$ & $\begin{array}{l}\text { S2 split could be physiological } \\
\text { or reversed }\end{array}$ & $\begin{array}{l}\text { S2 split could be physiologi- } \\
\text { cal or single, P2 louder than } \\
\text { A2 and transmitted to mitral } \\
\text { area. Ejection sound present }\end{array}$ \\
\hline
\end{tabular}

2. Normal semilunar valves with pulmonary valve is malposed-posterior to aortic valve, preventing its transmission to chest wall.

3. There is only one semilunar valve-truncus arteriosus.

Loud P2, as defined by audibility of P2 at apex, implies the presence of pulmonary hypertension. The only exception to this rule is in patients with ASD where there is clockwise rotation of heart, leading to audible $\mathrm{P} 2$ at apex even in the absence of $\mathrm{PH}$. Variations of second heart sound in Eisenmeneger syndrome has been tabulated below (- Table 12).

\section{Conclusion}

Understanding the physiologic mechanism of generation of second heart sound will lead one to appreciate the causes and consequences of the cardiovascular diseases on second heart sound.

\section{Conflict of Interest}

None.

\section{References}

1 Leatham A. The 2D Heart Sound Key To Auscultation of the Heart. Acta Cardiol 1964;19:395-416

2 RounanetJ. Analyse Des Bruits Du Coeur [Paris thesis]. 1832

3 Potain M. Note sur les dedublementsnormaux des bruits du coeur. Bull Mem Soc Med Hop Paris 1866;3:138

4 Byju's. Available at: https://byjus.com/physics/timbre/. Accessed February 25, 2020

5 Klabunde RE. Cardiovascular Physiology Concepts Philadelphia, PA: Lippincott Williams \& Wilkins; 2012

6 Shaver JA. Clinical implications of the hangout interval. Int J Cardiol 1984;5(3):391-398

7 Harris A, Sutton G. Second heart sound in normal subjects. Br Heart J 1968;30(6):739-742

8 Shafter HA. Splitting of the second heart sound. Am J Cardiol 1960;6:1013-1022

9 Saksena FB, Ranganathan N, Sivaciyan V. The Art and Science of Cardiac Physical Examination. Totowa, NJ: Humana Press; 2011

10 Stanford Medicine. Available at: https://stanfordmedicine25. stanford.edu/the25/cardiac.html. Accessed February 25, 2020 